\title{
Hematoma Expansion following Acute Intracerebral Hemorrhage
}

\author{
H. Bart Brouwers ${ }^{a-c}$ Steven M. Greenberg ${ }^{b, c}$ \\ ${ }^{a}$ Center for Human Genetic Research, ${ }^{b}$ Hemorrhagic Stroke Research Group, and ${ }^{\mathrm{C} J}$. Philip Kistler Stroke Research \\ Center, Massachusetts General Hospital, Harvard Medical School, Boston, Mass., USA
}

\section{Key Words}

Intracerebral hemorrhage · Hematoma expansion · CT

angiography spot sign - Clinical trials · Functional outcome toma expansion is so far the only marker of outcome that is amenable to treatment and thus a potentially important therapeutic target.
Copyright $\odot 2013$ S. Karger AG, Basel

\begin{abstract}
Intracerebral hemorrhage $(\mathrm{ICH})$, the most devastating form of stroke, has no specific therapy proven to improve outcome by randomized controlled trial. Location and baseline hematoma volume are strong predictors of mortality, but are nonmodifiable by the time of diagnosis. Expansion of the initial hematoma is a further marker of poor prognosis that may be at least partly preventable. Several risk factors for hematoma expansion have been identified, including baseline ICH volume, early presentation after symptom onset, anticoagulation, and the $\mathrm{CT}$ angiography spot sign. Although the biological mechanisms of hematoma expansion remain unclear, accumulating evidence supports a model of ongoing secondary bleeding from ruptured adjacent vessels surrounding the initial bleeding site. Several large clinical trials testing therapies aimed at preventing hematoma expansion are in progress, including aggressive blood pressure reduction, treatment with recombinant factor Vlla guided by CT angiography findings, and surgical intervention for superficial hematomas without intraventricular extension. Hema-
\end{abstract}

\section{Introduction}

Spontaneous intracerebral hemorrhage (ICH) accounts for approximately $15 \%$ of all acute strokes and is the deadliest stroke subtype with one-month mortality rates of $40 \%[1,2]$. After the first year, more than $75 \%$ of all ICH patients are severely disabled or deceased [2]. This makes ICH a major public health problem in need of effective therapies, as no treatment has yet been proven effective.

Initial hematoma volume remains the strongest predictor of 30-day mortality and functional outcome [3]. Hematoma location is another factor influencing both short- and long-term outcome [4]. In addition, approximately $30 \%$ of patients continue to bleed and demonstrate significant hematoma expansion during hospitalization, which further aggravates outcome $[5,6]$.

Because ICH volume and location are determined upon presentation, hematoma expansion holds the po-

\section{KARGER}

E-Mail karger@karger.com

www.karger.com/ced
(C) 2013 S. Karger AG, Base

$1015-9770 / 13 / 0353-0195 \$ 38.00 / 0$
H. Bart Brouwers, MD

Center for Human Genetic Research - Rosand Lab, Massachusetts General Hospital Harvard Medical School, 185 Cambridge Street, CPZN-6818 Boston, MA 02114 (USA)

E-Mail brouwers@ chgr.mgh.harvard.edu 
tential for being the only modifiable predictor of outcome. Therapies preventing expansion could thus provide a key opportunity to decrease final ICH volume. Previous and ongoing clinical trials have focused on limiting expansion, using approaches such as recombinant factor VIIa (rFVIIa) or aggressive blood pressure reduction [79]. The specific targeting of hematoma expansion in clinical trials has yet to yield improvement of clinical outcome, however [7]. This may be partly related to the difficulty of identifying those individuals most likely to benefit from the intervention, i.e. those who will actually suffer hematoma expansion [10]. It is therefore important to understand the risk factors for expansion as well as its biological underpinnings and treatment opportunities. This review addresses those issues and proposes potential clinical applications and future directions.

\section{Hematoma Expansion}

\section{Definitions}

Different definitions have been used across studies to describe hematoma growth between the initial (baseline) CT and the follow-up CT, normally acquired within 24$72 \mathrm{~h}$ after the first CT. Most studies use a dichotomized outcome for hematoma expansion: with an absolute cutoff (typically $\geq 3, \geq 6$, or $\geq 12.5 \mathrm{ml}$ ), a proportional cut-off (typically $>26$ or $>33 \%$ ), or a combination of both [6]. The two largest ongoing clinical trials use $>33 \%$ or $>12.5 \mathrm{ml}$ (INTERACT2 [8]) and $\geq 33 \%$ (ATACH II [9]) as their dichotomized definition of hematoma expansion.

\section{Imaging}

The vast majority of studies assessing hematoma expansion have used CT as imaging modality, mainly because of its widespread availability [11]. Different volumetric assessment techniques are used to measure expansion, including $\mathrm{ABC} / 2, \mathrm{ABC} / 2$ with adjusted $\mathrm{C}$ values, planimetry, and $3 \mathrm{D}$ volume rendering. It is important to note the differences in accuracy between the different techniques, with the semi-automated techniques being more accurate compared to the $\mathrm{ABC} / 2$ method, especially in irregularly shaped hematomas [12].

CT angiography (CTA) is increasingly used for the diagnosis and prognostication of ICH. CTAs were initially obtained to visualize vascular abnormalities underlying $\mathrm{ICH}$, such as arteriovenous malformations, aneurysms, or neoplasms [13]. They now serve the additional purpose of visualizing contrast extravasation within the hematoma, commonly termed the 'spot sign', which corre- lates with expansion and poor functional outcome discussed in more detail below [14-16].

CT's widespread acute availability makes it the primary diagnostic modality for ICH. However, gradient recalled echo MRI is equally sensitive for diagnosing acute ICH [17]. An advantage of MRI over CT is its ability to detect microbleeds, indicative of underlying vascular disease and a risk factor for recurrent lobar ICH $[18,19]$.

\section{Timing}

The timing of imaging is essential when assessing hematoma expansion. Because expansion represents an intermediate phase between initial hematoma volume and the final (stabilized) volume, the ability to detect expansion depends on the point at which a patient is scanned within this timeframe. Although early presentation is associated with a higher likelihood of hematoma expansion $[20,21]$, a substantial subset of all expanders (up to $48 \%$ ) present at least $6 \mathrm{~h}$ after symptom onset [22]. Predicting and preventing expansion thus appears to be an important goal even in late-presenting patients.

\section{Frequency}

The frequency of hematoma expansion differs substantially across different studies, most likely because of variations in definition, time from symptom onset to initial CT, and volumetric assessment techniques. The definition of hematoma expansion influences the frequency of its detection and varies between 13 and $32 \%$ in patients presenting within $6 \mathrm{~h}$ of symptom onset [6]. Timing further influences expansion frequency; in patients scanned within $3 \mathrm{~h}$ of symptom onset, any degree of expansion is seen in up to $73 \%$ and significant expansion in approximately one third of patients [5]. In later timeframes, the frequency of significant hematoma expansion decreases to $11 \%$ for those presenting between 3 and $6 \mathrm{~h}$ of symptom onset, $11 \%$ after $6 \mathrm{~h}$, and $20 \%$ in patients who are 'found down' with symptoms [22]. The previously described variations in volumetric assessment techniques also account for some of the observed differences in expansion frequency [12].

\section{Pathophysiology}

Biology

Hematoma expansion is often conceptualized as a single vessel that bursts and continues to bleed, analogous to a bathtub with a persistently running tap. This model is easy to visualize and generally consistent with the higher likelihood of expansion in the early course of the hemorrhage $[20,21]$. There is no direct histopathologic support 
Fig. 1. CTA spot sign and hematoma expansion. CT and CTA of a 78-year-old male, showing an acute ICH. a The baseline CT shows an $18-\mathrm{ml} \mathrm{ICH}$ centered within the left parietal lobe without intraventricular extension. b CTA demonstrates multiple spot signs within the anterior portion of the hematoma. c A follow-up CT after $7 \mathrm{~h}$ shows significant expansion of the hemorrhage (final volume: $119 \mathrm{ml}$ ). The patient passed away the day after admission.
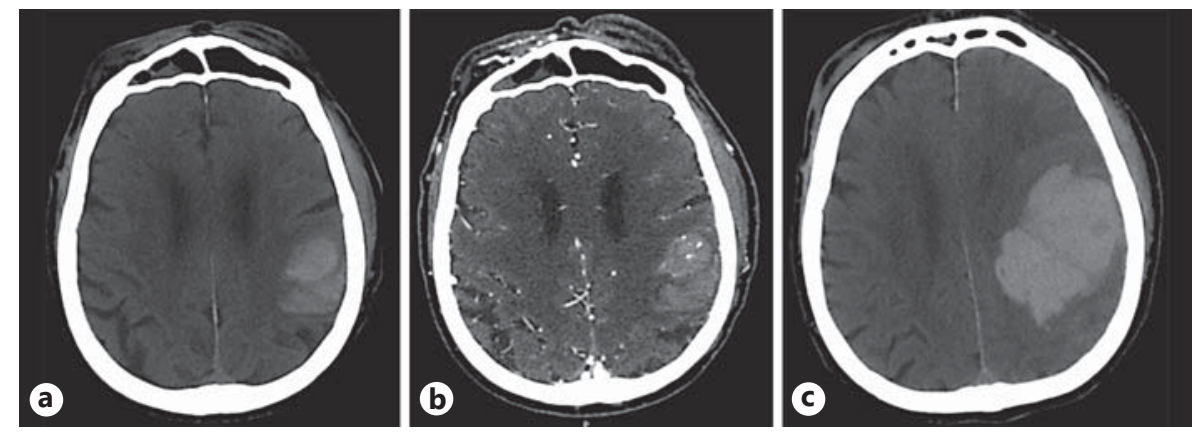

for a single persistently bleeding vessel, however. It is also somewhat difficult to reconcile with the clinical observation that hematoma expansion can occur hours after the initial bleeding $[22,23]$.

An alternative 'avalanche' model for hemorrhage expansion was proposed by Dr. C. Miller Fisher in the early 1970 's. Based on Dr. Fisher's observation of multiple recently ruptured vessels at the periphery of serially sectioned hematomas, this model describes the process of hematoma growth as secondary mechanical shearing of neighboring vessels caused by expansion of the initial hemorrhage [24]. Several observations add support to this model. One is that hemorrhage volumes tend to occur in a bimodal distribution as either small 'microbleeds' or larger 'macrobleeds' consistent with the feed-forward aspect of the avalanche process [25]. A model of secondary vessel shearing is also indirectly supported by genetic data showing the apolipoprotein $\mathrm{E}$ (APOE) $\varepsilon 2$ allele to be associated with hematoma expansion in lobar ICH [26]. As this allele correlates with an increased breakdown of vessel walls affected by cerebral amyloid angiopathy, it is reasonable to speculate that it may also increase the walls' fragility to mechanical rupture $[27,28]$. Finally, the avalanche model is consistent with the interpretation of the CTA spot sign as sites of active bleeding (visualized as contrast extravasation) following venous contrast injection. Multiple spot signs within a single hematoma are common $[29,30]$ (fig. 1), suggesting simultaneous bleeding from several surrounding vessels as would be expected in an avalanche of secondary shearing rather than a single persistently bleeding vessel.

\section{Computational Model}

A recent publication sought to create a computational simulation of the avalanche model that would identify the characteristics of hemorrhages generated by simulated rupture of adjacent vessels surrounding an initial site of

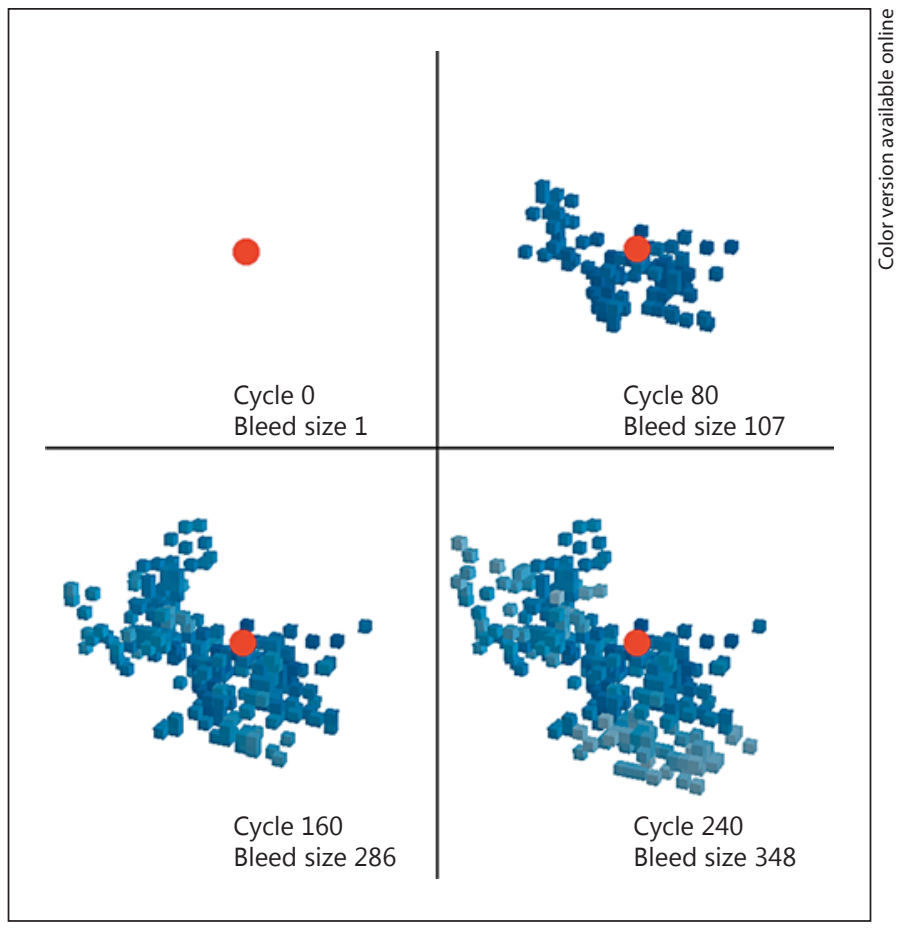

Fig. 2. Computational model hematoma expansion. Snapshots of a computational simulation of the 'avalanche model' for hematoma expansion. The initially ruptured small vessel is shown as a large dot and the secondary mechanical shearing of adjacent vessels is shown as differently shaded squares (from [31]).

bleeding [31] (fig. 2). The results of the simulation indicated that, under particular ranges of parameters for likelihood of secondary vessel rupture and rate of hemorrhage decay (simulating coagulation), this model would yield a bimodal distribution of microbleeds and macrobleeds similar to that observed in lobar ICH patients [25]. The effect of anticoagulation was further simulated by extending the rate of hemorrhage decay, which in the mod- 
el led to more macrobleed events, larger final ICH volumes, faster rates of expansion, and prolonged durations of hematoma expansion [31]. This model supports the plausibility of the avalanche model and generates further predictions potentially testable in future studies.

\section{Risk Factors}

Several risk factors for hematoma expansion have been identified over the last decade. Initial ICH volume is strongly related to expansion risk: larger hematomas are more likely to expand $[32,33]$. Two other risk factors include early presentation after symptom onset [14, 22, 32] and anticoagulation use $[26,34,35]$. As noted above, the possession of an APOE $\varepsilon 2$ allele also increases the risk of expansion in lobar ICH [26]. The final important risk factor is the CTA spot sign; a marker of active bleeding that has been studied extensively over the last five years. The spot sign has been shown to be a strong and independent predictor of hematoma expansion, poor functional outcome, and death [14-16, 36]. The major challenge is its relatively low sensitivity of $51 \%$ in the recent prospective PREDICT trial [16], which highlights the considerable number of patients who will suffer expansion despite the absence of a spot sign on CTA.

\section{Outcome}

Expansion of the initial hematoma strongly influences morbidity and mortality. The hazard ratio of mortality goes up by $5 \%$ with every $10 \%$ increase in $\mathrm{ICH}$ volume. In addition, each milliliter absolute increase in volume makes patient outcomes 7\% more likely to shift from independence to dependence, as measured by the 6-point modified Rankin Scale [5]. Numerous other studies confirm the relationship of expansion with neurological deterioration, poor functional outcome, and death $[6,20$, 37]. These relationships appear to be independent of which definition is used for hematoma expansion [6]. Moreover, data from the INTERACT1 trial suggest a clear dose-response relationship between the magnitude of hematoma expansion and functional outcome and mortality, when using either absolute or proportional definitions of expansion [37].

\section{Treatment and Ongoing Trials}

To date, no individual treatment for ICH has shown benefit in a randomized controlled trial, although specialized treatment provided by a neuroscience ICU does appear to reduce mortality [38]. Because of its strong relationship with outcome and the potential to alter its course, hematoma expansion is an appealing therapeutic target. Candidate treatments aimed at improving $\mathrm{ICH}$ outcome - potentially by reducing hematoma expansion - can be divided into medical and surgical interventions.

\section{Medical Interventions}

Several medical therapies have been studied in randomized controlled trials over the last decades. In the eighties, corticosteroids were found not to be beneficial in the treatment of supratentorial ICH and were even associated with increased complication rates [39]. The 2008 phase III randomized rFVIIa trial was among the most anticipated studies in the treatment era of ICH. With a phase II trial showing beneficial effects on hematoma expansion, mortality, and functional outcome, the first effective treatment for ICH appeared close [40]. Although the phase III trial confirmed the effect on hematoma expansion, it did not find benefit in clinical outcome [7]. One possible explanation for the absence of clinical benefit is that the majority of patients randomized to rFVIIa were not destined to suffer hematoma expansion, but were nonetheless exposed to this agent's potential thromboembolic complications. This explanation argues for using better selection criteria for identifying those patients who are indeed destined to undergo expansion [10]. Two phase II clinical trials are currently testing the CTA spot sign as such a selection tool for treatment with rFVIIa: STOP-IT (ClinicalTrials.gov NCT00810888) and SPOTLIGHT (ClinicalTrials.gov NCT01359202).

Another candidate approach to limit hematoma expansion is aggressive blood pressure reduction for acute ICH. Two pilot studies have shown that aggressive lowering of blood pressure is safe and feasible in the acute phase following symptom onset. As a secondary endpoint, hematoma expansion also appeared to be limited in patients treated with the intensive blood pressure regime [41, 42]. The second phase of both trials, INTERACT2 [8] and ATACH II [9], are currently underway, with the results of INTERACT2 expected in 2013.

\section{Surgical Interventions}

Surgical interventions have not been proven beneficial in randomized controlled trials, with the exception of cerebellar ICH $[43,44]$. The largest surgical trial, STICH, did not show benefit for unselected ICH patients randomized to early surgery (at a median of $30 \mathrm{~h}$ ) [45]. Subsequent systematic reviews, however, suggested potential positive effects of surgical evacuation in certain subgroups [46, 47]. STICH II is therefore assessing if early surgery for lobar ICH, within $1 \mathrm{~cm}$ of the cortex and without intra- 
ventricular extension, may be beneficial [48]. Minimally invasive surgical techniques also provide promising evidence for future surgical treatment options in acute ICH [49-51]. It remains unclear whether the possible benefits of surgical clot removal are related to preventing subsequent expansion or rather to reduced pathogenic effects of the clot itself, such as mass effect or neurotoxicity related to hemoglobin, thrombin, and iron accumulation [52].

\section{Challenges and Future Directions}

Hematoma expansion is an attractive endpoint for clinical trials because of its correlation with outcome and the potential to intervene to prevent its occurrence. Substantial challenges remain, however, which will need to be addressed before successful translation to clinical outcomes.

One major challenge will be to identify conditions under which preventing hematoma expansion actually improves clinical outcome. This point is underlined by the observation that, although both rFVIIa trials found that hematoma expansion could be reduced, functional outcome in the phase III trial was not improved $[7,40]$. As it seems unlikely that hematoma expansion is clinically meaningless, the more plausible explanation is that the benefits of reducing expansion may have been outweighed by the thromboembolic risks of rFVIIa, particularly in those subjects who would not have expanded even without active treatment. By this reasoning, therapies that carry risk as well as benefit may need to be focused on selected patients at highest risk for subsequent hematoma expansion.

This consideration raises the second challenge of identifying more reliable predictors of hematoma expansion. Early presentation (within 4-6 h) was used in the blood pressure reduction and rFVIIa trials as a surrogate for expansion, but only up to $40 \%$ of those patients actually suffer significant hematoma expansion [20]. The CTA spot sign was found to have a higher positive predictive value of $61 \%$ in a recent prospective study, and it might therefore be a better (although still imperfect) predictor of expansion [16, 53]. Identifying more accurate predictors of hematoma expansion thus remains a key research priority.

A third challenge is that those patients at highest risk for expansion may have poor outcomes even if expansion is fully prevented. This concern is raised by the observation that the main risk factors for hematoma expansion, such as baseline ICH volume and anticoagulation use, also independently worsen ICH outcome [3, 34]. Our poor ability to reverse these accompanying factors might be indeed another reason behind the negative results of the phase III rFVIIa trial. This consideration raises the possibility that treatments that go beyond preventing expansion, potentially including surgical hematoma evacuation (as currently tested in the STICH II trial [48]) or neuroprotective agents to salvage damaged brain tissue (such as deferoxamine [54]), may be required for demonstrably improved ICH outcome.

A final important consideration regarding hematoma expansion is the window it provides on the broader process of ICH pathogenesis. The expansion that can be measured after clinical presentation presumably represents only the tail end of an event that began with the first rupture of a diseased small vessel and progressively grew into a symptomatic macrobleed [24]. Understanding the mechanisms that underlie this process, such as the secondary rupture of adjacent vessels described above, has the potential to lead not only to acute treatments for use after presentation, but also to novel preventive strategies for keeping small vessel ruptures from evolving into symptomatic macroscopic events.

Although these major challenges are still unsolved, substantial progress has been made over the last decades to better understand and potentially treat hematoma expansion. Hematoma expansion remains the most readily modifiable marker of outcome, and thus an intriguing therapeutic target for intracerebral hemorrhage.

\section{Funding}

All funding entities had no involvement in the study design, data collection, analysis, and interpretation, writing of the manuscript and in the decision to submit for publication. The project described was supported by grant No. R01AG026484 from the National Institutes of Health (NIH). H.B. Brouwers was supported by the NIH - National Institute of Neurological Disorders and Stroke (NINDS) SPOTRIAS fellowship grant P50NS051343. The content is solely the responsibility of the authors and does not necessarily represent the official views of the NIH or the NINDS.

\section{Disclosure Statement}

H.B. Brouwers: no conflicts of interest; S.M. Greenberg: research grants from the NIH, honoraria from Medtronic and Pfizer, consultant/on the advisory board of Hoffmann-La Roche, Janssen Alzheimer Immunotherapy, and Bristol-Myers Squibb Company. 


\section{References}

1 Qureshi AI, Mendelow AD, Hanley DF: Intracerebral haemorrhage. Lancet 2009;373: 1632-1644.

$>2$ van Asch CJ, Luitse MJ, Rinkel GJ, van der Tweel I, Algra A, Klijn CJ: Incidence, case fatality, and functional outcome of intracerebral haemorrhage over time, according to age, sex, and ethnic origin: a systematic review and meta-analysis. Lancet Neurol 2010;9:167176.

$>3$ Broderick JP, Brott TG, Duldner JE, Tomsick T, Huster G: Volume of intracerebral hemorrhage. A powerful and easy-to-use predictor of 30-day mortality. Stroke 1993;24:987-993.

4 Flaherty ML, Haverbusch M, Sekar P, Kissela B, Kleindorfer D, Moomaw CJ, et al: Longterm mortality after intracerebral hemorrhage. Neurology 2006;66:1182-1186.

$\checkmark 5$ Davis SM, Broderick J, Hennerici M, Brun NC, Diringer MN, Mayer SA, et al: Hematoma growth is a determinant of mortality and poor outcome after intracerebral hemorrhage. Neurology 2006;66:1175-1181.

$\checkmark 6$ Dowlatshahi D, Demchuk AM, Flaherty ML, Ali M, Lyden PL, Smith EE, et al: Defining hematoma expansion in intracerebral hemorrhage: relationship with patient outcomes. Neurology 2011;76:1238-1244.

$>7$ Mayer SA, Brun NC, Begtrup K, Broderick J, Davis S, Diringer MN, et al: Efficacy and safety of recombinant activated factor VII for acute intracerebral hemorrhage. N Engl J Med 2008;358:2127-2137.

$>8$ Delcourt C, Huang Y, Wang J, Heeley E, Lindley R, Stapf C, et al: The second (main) phase of an open, randomised, multicentre study to investigate the effectiveness of an intensive blood pressure reduction in acute cerebral haemorrhage trial (INTERACT2). Int J Stroke 2010;5:110-116.

-9 Qureshi AI, Palesch YY: Antihypertensive Treatment of Acute Cerebral Hemorrhage (ATACH) II: design, methods, and rationale. Neurocrit Care 2011;15:559-576.

10 Mayer SA, Davis SM, Skolnick BE, Brun NC, Begtrup K, Broderick JP, et al: Can a subset of intracerebral hemorrhage patients benefit from hemostatic therapy with recombinant activated factor VII? Stroke 2009;40:833-840.

11 Ginde AA, Foianini A, Renner DM, Valley M, Camargo CA Jr: Availability and quality of computed tomography and magnetic resonance imaging equipment in US emergency departments. Acad Emerg Med 2008;15:780783.

12 Divani AA, Majidi S, Luo X, Souslian FG, Zhang J, Abosch A, et al: The ABCs of accurate volumetric measurement of cerebral hematoma. Stroke 2011;42:1569-1574.

13 Delgado Almandoz JE, Romero JM: Advanced CT imaging in the evaluation of hemorrhagic stroke. Neuroimaging Clin N Am 2011;21:197-213, ix.
14 Goldstein JN, Fazen LE, Snider R, Schwab K, Greenberg SM, Smith EE, et al: Contrast extravasation on CT angiography predicts hematoma expansion in intracerebral hemorrhage. Neurology 2007;68:889-894.

15 Wada R, Aviv RI, Fox AJ, Sahlas DJ, Gladstone DJ, Tomlinson G, et al: CT angiography 'spot sign' predicts hematoma expansion in acute intracerebral hemorrhage. Stroke 2007; 38:1257-1262.

16 Demchuk AM, Dowlatshahi D, RodriguezLuna D, Molina CA, Blas YS, Dzialowski I, et al: Prediction of haematoma growth and outcome in patients with intracerebral haemorrhage using the CT-angiography spot sign (PREDICT): a prospective observational study. Lancet Neurol 2012;11:307-314.

$>17$ Kidwell CS, Chalela JA, Saver JL, Starkman S, Hill MD, Demchuk AM, et al: Comparison of MRI and CT for detection of acute intracerebral hemorrhage. JAMA 2004;292:18231830 .

18 Greenberg SM, Eng JA, Ning M, Smith EE, Rosand J: Hemorrhage burden predicts recurrent intracerebral hemorrhage after lobar hemorrhage. Stroke 2004;35:1415-1420.

19 Greenberg SM, Vernooij MW, Cordonnier C, Viswanathan A, Al-Shahi Salman R, Warach $\mathrm{S}$, et al: Cerebral microbleeds: a guide to detection and interpretation. Lancet Neurol 2009;8:165-174.

20 Brott T, Broderick J, Kothari R, Barsan W, Tomsick T, Sauerbeck L, et al: Early hemorrhage growth in patients with intracerebral hemorrhage. Stroke 1997;28:1-5.

21 Mayer SA: Ultra-early hemostatic therapy for intracerebral hemorrhage. Stroke 2003;34: 224-229.

22 Brouwers HB, Falcone GJ, McNamara KA, Ayres AM, Oleinik A, Schwab K, et al: CTA spot sign predicts hematoma expansion in patients with delayed presentation after intracerebral hemorrhage. Neurocrit Care 2012;17: 421-428.

23 Kim J, Smith A, Hemphill JC3rd, Smith WS Lu Y, Dillon WP, et al: Contrast extravasation on CT predicts mortality in primary intracerebral hemorrhage. AJNR Am J Neuroradiol 2008;29:520-525.

24 Fisher CM: Pathological observations in hypertensive cerebral hemorrhage. J Neuropathol Exp Neurol 1971;30:536-550.

25 Greenberg SM, Nandigam RN, Delgado P, Betensky RA, Rosand J, Viswanathan A, et al: Microbleeds versus macrobleeds: evidence for distinct entities. Stroke 2009;40:23822386.

26 Brouwers HB, Biffi A, Ayres AM, Schwab K, Cortellini L, Romero JM, et al: Apolipoprotein E genotype predicts hematoma expansion in lobar intracerebral hemorrhage. Stroke 2012;43:1490-1495.
27 Greenberg SM, Vonsattel JP, Segal AZ, Chiu RI, Clatworthy AE, Liao A, et al: Association of apolipoprotein E epsilon2 and vasculopathy in cerebral amyloid angiopathy. Neurology 1998;50:961-965.

28 McCarron MO, Nicoll JA, Stewart J, Ironside JW, Mann DM, Love S, et al: The apolipoprotein E epsilon2 allele and the pathological features in cerebral amyloid angiopathy-related hemorrhage. J Neuropathol Exp Neurol 1999; 58:711-718.

29 Delgado Almandoz JE, Yoo AJ, Stone MJ, Schaefer PW, Goldstein JN, Rosand J, et al: Systematic characterization of the computed tomography angiography spot sign in primary intracerebral hemorrhage identifies patients at highest risk for hematoma expansion: the spot sign score. Stroke 2009;40: 2994-3000.

30 Brouwers HB, Biffi A, McNamara KA, Ayres AM, Valant V, Schwab K, et al: Apolipoprotein $\mathrm{E}$ genotype is associated with $\mathrm{CT}$ angiography spot sign in lobar intracerebral hemorrhage. Stroke 2012;43:2120-2125.

31 Greenberg CH, Frosch MP, Goldstein JN, Rosand J, Greenberg SM: Modeling intracerebral hemorrhage growth and response to anticoagulation. PLoS One 2012; 7:e48458.

-32 Broderick JP, Diringer MN, Hill MD, Brun NC, Mayer SA, Steiner T, et al: Determinants of intracerebral hemorrhage growth: an exploratory analysis. Stroke 2007;38:10721075.

33 Dowlatshahi D, Smith EE, Flaherty ML, Ali M, Lyden P, Demchuk AM, et al: Small intracerebral haemorrhages are associated with less haematoma expansion and better outcomes. Int J Stroke 2011;6:201-206.

34 Flibotte JJ, Hagan N, O’Donnell J, Greenberg SM, Rosand J: Warfarin, hematoma expansion, and outcome of intracerebral hemorrhage. Neurology 2004;63:1059-1064.

-35 Cucchiara B, Messe S, Sansing L, Kasner S, Lyden P; CHANT Investigators: Hematoma growth in oral anticoagulant related intracerebral hemorrhage. Stroke 2008;39:29932996.

36 Delgado Almandoz JE, Yoo AJ, Stone MJ, Schaefer PW, Oleinik A, Brouwers HB, et al: The spot sign score in primary intracerebral hemorrhage identifies patients at highest risk of in-hospital mortality and poor outcome among survivors. Stroke 2010;41:54-60.

37 Delcourt C, Huang Y, Arima H, Chalmers J, Davis SM, Heeley EL, et al: Hematoma growth and outcomes in intracerebral hemorrhage: the INTERACT1 study. Neurology 2012;79: 314-319.

38 Diringer MN, Edwards DF: Admission to a neurologic/neurosurgical intensive care unit is associated with reduced mortality rate after intracerebral hemorrhage. Crit Care Med 2001;29:635-640. 
39 Poungvarin N, Bhoopat W, Viriyavejakul A, Rodprasert P, Buranasiri P, Sukondhabhant $S$, et al: Effects of dexamethasone in primary supratentorial intracerebral hemorrhage. $\mathrm{N}$ Engl J Med 1987;316:1229-1233.

40 Mayer SA, Brun NC, Begtrup K, Broderick J, Davis S, Diringer MN, et al: Recombinant activated factor VII for acute intracerebral hemorrhage. N Engl J Med 2005;352:777-785.

41 Anderson CS, Huang Y, Wang JG, Arima H, Neal B, Peng B, et al: Intensive blood pressure reduction in acute cerebral haemorrhage trial (INTERACT): a randomised pilot trial. Lancet Neurol 2008;7:391-399.

-42 Qureshi AI, Palesch YY, Martin R, Novitzke J, Cruz-Flores S, Ehtisham A, et al: Effect of systolic blood pressure reduction on hematoma expansion, perihematomal edema, and 3-month outcome among patients with intracerebral hemorrhage: results from the antihypertensive treatment of acute cerebral hemorrhage study. Arch Neurol 2010;67:570-576.

43 Da Pian R, Bazzan A, Pasqualin A: Surgical versus medical treatment of spontaneous posterior fossa haematomas: a cooperative study on 205 cases. Neurol Res 1984;6:145-151.
44 van Loon J, Van Calenbergh F, Goffin J, Plets $\mathrm{C}$ : Controversies in the management of spontaneous cerebellar haemorrhage. A consecutive series of 49 cases and review of the literature. Acta Neurochir (Wien) 1993;122:187193.

45 Mendelow AD, Gregson BA, Fernandes HM, Murray GD, Teasdale GM, Hope DT, et al: Early surgery versus initial conservative treatment in patients with spontaneous supratentorial intracerebral haematomas in the International Surgical Trial in Intracerebral Haemorrhage (STICH): a randomised trial. Lancet 2005;365:387-397.

46 Prasad K, Mendelow AD, Gregson B: Surgery for primary supratentorial intracerebral haemorrhage. Cochrane Database Syst Rev 2008;4:CD000200.

47 Gregson BA, Broderick JP, Auer LM, Batjer $\mathrm{H}$, Chen XC, Juvela S, et al: Individual patient data subgroup meta-analysis of surgery for spontaneous supratentorial intracerebral hemorrhage. Stroke 2012;43:1496-1504.

48 Mendelow AD, Gregson BA, Mitchell PM, Murray GD, Rowan EN, Gholkar AR, et al: Surgical trial in lobar intracerebral haemorrhage (STICH II) protocol. Trials 2011;12: 124.

-49 Teernstra OP, Evers SM, Lodder J, Leffers P, Franke CL, Blaauw G, et al: Stereotactic treatment of intracerebral hematoma by means of a plasminogen activator: a multicenter randomized controlled trial (SICHPA). Stroke 2003;34:968-974.
50 Vespa P, McArthur D, Miller C, O’Phelan K, Frazee J, Kidwell C, et al: Frameless stereotactic aspiration and thrombolysis of deep intracerebral hemorrhage is associated with reduction of hemorrhage volume and neurological improvement. Neurocrit Care 2005;2:274281.

51 Newell DW, Shah MM, Wilcox R, Hansmann DR, Melnychuk E, Muschelli J, et al: Minimally invasive evacuation of spontaneous intracerebral hemorrhage using sonothrombolysis. J Neurosurg 2011;115:592-601.

52 Xi G, Keep RF, Hoff JT: Mechanisms of brain injury after intracerebral haemorrhage. Lancet Neurol 2006;5:53-63.

53 Brouwers HB, Goldstein JN, Romero JM, Rosand J: Clinical applications of the computed tomography angiography spot sign in acute intracerebral hemorrhage: a review. Stroke 2012;43:3427-3432.

54 Selim M, Yeatts S, Goldstein JN, Gomes J, Greenberg S, Morgenstern LB, et al:. Safety and tolerability of deferoxamine mesylate in patients with acute intracerebral hemorrhage. Stroke 2011;42:3067-307. 